\title{
Aspectos clínicos, epidemiológicos e diagnóstico da infecção por Trypanosoma vivax em rebanho bovino no estado do Maranhão ${ }^{1}$
}

\author{
Hélio D. Pereira², Sara V.D. Simões ${ }^{2 *}$, Francisco A.L. Souza ${ }^{3}$, Júlia A.G. Silveira ${ }^{4}$, \\ Múcio F.B. Ribeiro ${ }^{4}$, Fabiano A. Cadioli ${ }^{5}$ e Paulo H. Sampaio ${ }^{6}$
}

\begin{abstract}
Pereira H.D., Simões S.V.D., Souza F.A.L., Silveira J.A.G., Ribeiro M.F.B., Cadioli F.A. \& Sampaio P.H. 2018. [Clinical and epidemiological aspects and diagnosis of Trypanosoma vivax infection in a cattle herd, state of Maranhão, Brazil.] Aspectos clínicos, epidemiológicos e diagnóstico da infecção por Trypanosoma vivax em rebanho bovino no estado do Maranhão. Pesquisa Veterinária Brasileira 38(5):896-901. Departamento de Ciências Veterinárias, Centro de Ciências Agrárias, Universidade Federal da Paraíba, Rodovia PB-079, Areia, PB 58397-000, Brazil. E-mail: saravdsimoes@gmail.com

The objective of this study was to investigate the occurrence of trypanosomiasis in a dairy farm in municipality of Timon, State of Maranhão, Brazil. The owner reported abortus, births of weak calves, and mortality of adult animals with progressive weight loss. Visits to the property were carried out to obtain the history, realize animal examination and blood collection for the Woo test, hemograms, serological tests for trypanosomiasis, leptospirosis, and neosporosis and PCR for molecular diagnosis of Trypanosoma vivax. The identification of animals with low values in the hematocrit was the main hematological alteration identified in the herd. Two animals were positive in the Woo test and trypanosomes were visualized in blood smears, confirmed by molecular diagnosis as T. vivax. It was identified that $95.23 \%$ (40/42) of the animals with low hematocrit were serologically positive for T. vivax. The conditions identified in the property as an environment propitious to mechanical vectors, the presence of wild animals and the introduction of animals from states where trypanosomiasis outbreaks had already been reported were probably associated with the introduction and dissemination of the agent in the herd. The high number of serologically positive animals for trypanosomiasis $82.51 \%(151 / 183)$ shows that almost all the herd had contact with the agent. The rapid establishment of control measures, including the use of trypanocidal drugs, contributed to the control of the outbreak. The study allowed confirming the occurrence of another outbreak of trypanosomiasis in Brazil. The clinical diagnosis of the disease was difficult by the similarity of the clinical signs of trypanosomiasis with other diseases and the possibility of association of two or more diseases in the same patient, which emphasizes the importance of establishing adequate diagnostic measures as a way to avoid the dissemination of the disease and to minimize the economic losses of the producers.
\end{abstract}

INDEX TERMS: Trypanosoma vivax, trypasomiasis, cattle, epidemiology, hemoparasites, parasitoses.

\footnotetext{
${ }^{1}$ Recebido em 19 de fevereiro de 2017.

Aceito para publicação em 14 de abril de 2017.

2 Programa de Pós-Graduação em Ciência Animal, Curso de Medicina Veterinária, Departamento de Ciências Veterinárias, Centro de Ciências Agrárias, Universidade Federal da Paraíba (UFPB), Rodovia PB-079, Areia, PB 58397-000, Brasil.*Autor para correspondência: saravdsimoes@gmail.com

${ }^{3}$ Departamento de Morfologia e Fisiologia Animal, Universidade Federal Rural de Pernambuco (UFRPE), Rua Dom Manoel de Medeiros s/n, Dois Irmãos, Recife, PE 52171-900, Brasil.
}

\footnotetext{
${ }^{4}$ Programa de Pós-Graduação em Parasitologia, Instituto de Ciências Biológicas, Universidade Federal de Minas Gerais (UFMG), Av. Antônio Carlos 6627, Belo Horizonte, MG 31270-901, Brasil.

${ }^{5}$ Curso de Medicina Veterinária, Departamento de Clínica, Cirurgia e Reprodução Animal, Faculdade de Medicina Veterinária (FMV), Universidade Estadual Paulista (Unesp), Rua Clóvis Pestana 793, Araçatuba, SP 16050-680, Brasil.

${ }^{6}$ Programa de Pós-Graduação em Medicina Veterinária, Faculdade de Ciências Agrárias e Veterinárias, Universidade Estadual Paulista (Unesp), Via de acesso Prof. Paulo Donato Castellane, Jaboticabal, SP 14884-900, Brasil.
} 
RESUMO.- 0 objetivo desse estudo foi investigar a ocorrência de tripanossomose em uma propriedade leiteira no município de Timon no estado do Maranhão, Brasil. 0 proprietário relatava histórico de abortos, nascimentos de crias fracas e mortalidade de animais adultos com perda progressiva de peso. Foram realizadas visitas à propriedade para obtenção do histórico, exame dos animais e coleta de sangue para realização do teste de Woo, hemogramas, testes sorológicos para pesquisa de anticorpos contra tripanossomose, leptospirose, e neosporose e PCR para diagnóstico molecular de Trypanosoma vivax. A identificação de animais com baixos valores no hematócrito foi a principal alteração hematológica identificada no rebanho. Dois animais foram positivos no teste de Woo, sendo visualizados tripanossomas em esfregaços sanguíneos, confirmados por meio de diagnóstico molecular como sendo T. vivax. Identificouse que 95,23\% (40/42) dos animais com hematócrito baixo foram sorologicamente positivos para T. vivax. As condições identificadas na propriedade, como ambiente propício aos vetores mecânicos, a presença de animais silvestres e a introdução de animais de estados onde já haviam sido registrados surtos de tripanossomose provavelmente estiveram associadas à introdução e disseminação do agente no rebanho. O elevado número de animais sorologicamente positivos para tripanossomose 82,51\% (151/183) demonstra que praticamente todo o rebanho teve contato com o agente. 0 rápido estabelecimento das medidas de controle, entre elas a utilização das drogas tripanocidas, contribuiu para o controle do surto. 0 estudo permitiu comprovar a ocorrência de mais um surto de tripanossomíase tripanossomose no Brasil. O diagnóstico clínico da enfermidade foi dificultado pela semelhança dos sinais clínicos com outras enfermidades e pela possibilidade da associação de duas ou mais doenças no mesmo paciente, o que ressalta a importância do estabelecimento de medidas diagnósticas adequadas como forma de evitar a disseminação da enfermidade e minimizar as perdas econômicas dos produtores.

TERMOS DE INDEXAÇÃO: Trypanosoma vivax, tripanossomose, bovino, epidemiologia, hemoparasitas, parasitoses.

\section{INTRODUÇÃO}

Tripanossomoses são doenças provocadas por protozoários do gênero Trypanosoma, que têm distribuição cosmopolita e importância econômica na África, em áreas ocupadas pelo seu vetor biológico, a mosca tsé-tsé (Batista et al. 2008). A movimentação de animais infectados para áreas livres da enfermidade e a capacidade do agente ser transmitido mecanicamente por insetos hematófagos permitiu a disseminação de T. vivax para a América Central, América do Sul e Caribe (Silva et al. 2003). Nos últimos anos tem-se observado registros de surtos da enfermidade ocasionada por T. vivax em diversos estados do Brasil, ocasionando mortes de animais e graves perdas econômicas, que vão desde perda de peso, abortos, problemas reprodutivos, redução da produção de carne e leite e custos com medicamentos, que influenciam diretamente a continuação e expansão da atividade pecuária. Os surtos ocorreram no Amapá (Serra Freire 1981), Mato Grosso do Sul (Paiva et al. 1997), Tocantins (Linhares et al. 2006), e Minas Gerais (Carvalho et al. 2008). Essa disseminação tem ocasionado preocupação, pois os pecuaristas por não terem conhecimento da enfermidade em suas regiões, das formas de transmissão da doença, e em muitos casos por desconheceram o tratamento adequado, não realizam medidas de prevenção, confundem os sinais da doença com outras enfermidades e tratam os animais inadequadamente. Essa situação vem provavelmente acelerando o processo de transmissão da enfermidade para áreas livres, principalmente devido ao comércio de animais infectados para áreas livres.

Objetivou-se com esse estudo investigar a ocorrência de tripanossomose em rebanho bovino no município de Timon, descrever aspectos clínicos e epidemiológicos da enfermidade, as medidas de controle instituídas e contribuir com o conhecimento da enfermidade na região.

\section{MATERIAL E MÉTODOS}

O estudo foi realizado no ano de 2015 em uma propriedade leiteira situada no município de Timon, Maranhão, com área física de 320 hectares. 0 proprietário relatava histórico de abortos, nascimentos de crias fracas e mortalidade de animais adultos com perda progressiva de peso. No período do estudo foram realizadas três visitas à propriedade para obtenção de informações sobre o rebanho, histórico do problema, realização de exames clínicos, coleta de materiais para exames e discussão de estratégias de controle.

Na primeira visita realizou-se exame físico em seis vacas com sinais clínicos crônicos. Amostras de sangue desses animais, de duas vacas que haviam abortado recentemente e de mais quatro bezerros com desenvolvimento inadequado foram colhidas na veia marginal da orelha, em tubos de micro-hematócrito com heparina, e submetidas à centrifugação para observação direta do capilar ao microscópio óptico para pesquisa de tripanossomas (Técnica de Woo 1970). Em seguida foram realizados esfregaços de capa leucocitária, sendo as lâminas fixadas em metanol e coradas pelo método de Giemsa, sendo esses examinados ao microscópio óptico em imersão. Amostra de sangue de um bezerro com grave perda de peso e mucosas pálidas foi colhida para realização de hemograma.

As amostras de sangue dos animais suspeitos no teste de Woo foram congeladas e encaminhadas para o laboratório de Patologia Animal da Universidade Federal do Piauí para extração do DNA e realização de PCR baseando-se na metodologia utilizada por Ventura et al. (2001), adaptado por Cuglovici et al. (2010). Nesta reação foram utilizados os primers TviSL1 e TviSL2 que amplificam 210 pares de base. Amostras também foram enviadas para o Laboratório de Imunoparasitologia Veterinária do Departamento de Patologia Veterinária da UNESP, Campus de Jaboticabal.

Ainda na ocasião da primeira visita, 75 amostras de sangue de vacas do rebanho foram colhidas, sendo 25 provenientes de animais que tinham abortado ou parido bezerros fracos, 25 de vacas prenhes sem qualquer manifestação clínica e 25 de animais que tinham parido normalmente. Foram solicitados para esses animais testes para tripanossomose (75 animais) leptospirose (45 animais) e neosporose (45 animais). Os testes para leptospirose e neosporose foram realizados no Instituto Biológico em São Paulo.

0 método sorológico utilizado para a tripanossomose foi à reação de imunofluorescência indireta (RIFI). Um total de 183 animais foi avaliado. 0 teste sorológico utilizado para detecção de anticorpos contra Neospora caninum foi o ELISA utilizando kit IDEXX e para leptospirose foi a soroaglutinação microscópica de acordo com metodologia descrita por Galton et al. (1965) e Cole Junior et al. (1973).

As medidas de controle instituídas, após identificação do Trypanosoma vivax no rebanho, foram o tratamento imediato dos animais com sinais clínicos com diaceturato de diminazene na dose de 7,0 mg/kg, tratamento posterior de todos os animais do 
rebanho com cloridrato de isometamidium na dose de $1,0 \mathrm{mg} / \mathrm{kg} \mathrm{IM}$ profunda, utilização de brincos inseticidas para controle das moscas e mutucas e controle da infestação por carrapatos de acordo com a metodologia proposta por Labruna et al. (2000).

Os animais foram tratados com cloridrato de isometamidium no momento da segunda visita a propriedade. Nessa ocasião optou-se por realizar também a coleta de sangue de todos os animais do rebanho para avaliação do hematócrito e coleta de soro, sendo encaminhadas mais 108 amostras para realização de testes sorológicos para tripanossomose.

Na terceira visita à propriedade foram avaliadas as medidas de controle instituídas e realizada coleta de sangue dos animais identificados inicialmente com VG baixo para avaliar, de forma indireta, a eficácia das medidas de controle.

\section{RESULTADOS}

0 rebanho era composto de 280 animais de diversas categorias, oriundos do cruzamento entre Gir e o Holandês, animais que apresentavam boa adaptabilidade à região e índices produtivos satisfatórios. Antes do início do problema o rebanho apresentava índices de natalidade muito satisfatórios, a taxa de mortalidade de animais jovens e adultos era muito baixa.

A produção média de leite girava em torno de 750 litros dia, em duas ordenhas, sendo o regime de criação semi-intensivo. Inicialmente o rebanho foi constituído de animais oriundos dos estados de Pernambuco e Minas Gerais. Com o passar dos anos, essa entrada de animais foi diminuindo, pois se deu início ao nascimento das crias dos animais que haviam sido adquiridos. 0 último lote introduzido no plantel tinha sido há cerca de um ano, oriundo do estado de Pernambuco e de outras propriedades do Maranhão, totalizando 15 animais. Durante as visitas foi observado que houve a introdução de um reprodutor vindo do estado de Pernambuco.

A propriedade dispunha de piquetes irrigados o ano inteiro, o que garantia boa disponibilidade de forragem durante $o$ ano. As vacas em lactação tinham acesso ao concentrado no momento da ordenha e recebiam complemento com cevada no cocho após a ordenha. As vacas secas e as novilhas eram criadas em piquetes com capim Massai (Megathyrsus maximus) e Andropogon (Andropogon gayanus kunth) e recebiam mineralização proteinada durante todo o ano em cochos. Os bezerros eram criados em piquetes com capim Tifton (Cynodon spp.), recebendo mineralização e concentrado nesses locais. Em relação ao manejo reprodutivo era utilizada a monta controlada. A propriedade mantinha uma área de mata de cerca de 90 hectares. A propriedade dispunha de uma lagoa com cerca de $1 \mathrm{~km}$ de comprimento e 4 metros de profundidade, localizada as margens dos piquetes. Na época chuvosa a lagoa aumentava a quantidade de água, pois a propriedade localizava-se próximo ao rio Parnaíba e na época chuvosa as águas do rio se acumulavam na lagoa. Devido à existência da área de mata eram visualizados muitos animais silvestres na propriedade, dentre eles capivaras, que tinham acesso direto a lagoa e aos piquetes dos animais. Na ocasião do surto foi visualizado um grande grupo de capivaras pastando junto aos animais no pasto.

Segundo o proprietário um problema sanitário recorrente no rebanho era a alta infestação por carrapatos. 0 controle da infestação era difícil de ser realizado, pois na região a alta temperatura, associada à elevada umidade nos pastos irrigados favoreciam a sobrevivência dos parasitos. Outro problema encontrado era a espoliação dos animais por moscas dos estábulos e mutucas, que se agravava mais nas épocas chuvosas, quando a quantidade de insetos aumentava significativamente. A presença de ratos nos galpões de armazenamento de milho também foi informada. Além disso, diversos cães habitavam as residências próximas aos currais e piquetes, tendo acesso aos mesmos e aos fetos abortados e placentas quando não eram devidamente descartadas.

Em relação à utilização de vacinas eram realizadas vacinações sistemáticas contra carbúnculo sintomático, brucelose, febre aftosa e raiva. Aplicações de vermífugos, inclusive nos animais adultos, também era uma prática realizada.

0 proprietário informou que no rebanho ocorriam abortos esporádicos, sendo registrados cinco casos em 2014, porém esses se intensificaram em 2015, sendo contabilizados 15 nos primeiros cinco meses do ano. No mesmo período que estavam ocorrendo os abortos foi observado que alguns animais apresentaram acentuada queda na produção de leite, perda de peso progressiva, pálpebras edemaciadas, lacrimejamento e problemas reprodutivos (repetições de cio e um reprodutor com perda da libido), sendo registrados seis óbitos de animais adultos. Esses sintomas não foram observados em todos os animais que abortaram, sendo o aborto muitas vezes a única alteração observada. Diversos medicamentos foram utilizados na tentativa de resolver o problema, incluindo antimicrobianos, imidocarb, diaceturato de diminazene, corticoides, antitóxicos e cálcio.

Os sinais clínicos identificados pelo proprietário nos animais que morreram foram cabeça baixa, lacrimejamento, edema de pálpebras, mucosas pálidas, aumento de volume nos linfonodos, salivação, secreção nasal mucosa abundante, membros rígidos e perda de peso. A morte ocorria entre um e 20 dias após o aparecimento dos sinais clínicos. Um animal apresentou urina escura e outro, após vários dias com os sinais clínicos, apresentou sintomatologia nervosa (andar em círculos, andar a esmo e cegueira), vindo a morrer após manifestação desses sinais.

Seis animais que manifestaram sinais clínicos, mas que não morreram, e continuavam cronicamente doentes, no exame físico apresentavam escore corporal inadequado, pelos secos e soltando com facilidade, desidratação, mucosas pálidas, lacrimejamento bilateral e dois apresentavam febre.

Dos animais que tiveram amostras sanguíneas avaliadas pelo teste de Woo dois foram positivos, um bezerro e uma das vacas cronicamente doentes. Nesses dois animais foram também visualizados tripanossoma em esfregaços sanguíneos, confirmados, por meio de diagnóstico molecular, como sendo Trypanosoma vivax. No hemograma do bezerro identificou-se hematócrito de $14 \%$, valor abaixo do referenciado para a espécie (24 a 36\%), anemia normocítica normocrômica, leucometria normal e presença de estruturas compatíveis com T. vivax e Anaplasma marginale.

$\mathrm{Na}$ avaliação dos hematócritos de todos os animais do rebanho identificou-se que 8,79\% (24/273) estavam também com valor inferior aos referenciados para a espécie.

Nos testes sorológicos para leptospirose foram encontrados títulos para os sorovares Icterohaemorrhagiae, Wolffi, Hardjo 
e Pomona. Os títulos variaram de 100 até 1600. Os sorovares de maior frequência foram Wolffi com 95,55\% (43/45), Icterohaemorrhagiae com 62,22\% (28/45), Hardjo com 44,44\% (20/45) e Pomona com 6,66\% (3/45).

Os testes sorológicos para tripanossomose identificaram um alto percentual de animais infectados no rebanho e ao se avaliar esse resultado conjuntamente com os valores dos hematócritos observou-se 95,23\% (40/42) dos animais com hematócrito baixo foram positivos para T. vivax. Além disso, 83,33\% (5/6) dos animais considerados cronicamente doentes foram também sorologicamente positivos para T. vivax.

Os resultados dos testes sorológicos para tripanossomose, leptospirose e neosporose estão apresentados no Quadro 1.

Após a utilização de duas doses de 7,0mg/kg de diaceturato de diminazene nos animais cronicamente enfermos foi observada melhora nos sinais clínicos. Após a aplicação do cloridrato de isometamidium, uso dos brincos inseticidas e estabelecimento de medidas de controle para os carrapatos a melhora no rebanho passou a ser mais evidente.

Em nova avaliação do hematócrito, nos animais que apresentavam valores inferiores ou nos limites inferiores de normalidade, realizada 54 dias após a implantação das medidas de controle, foi identificado que apenas um animal manteve o hematócrito baixo, inclusive com valor inferior ao apresentado na primeira avaliação.

Após a aplicação do cloridrato de isometamidium durante algumas semanas não foi registrado nenhum aborto, porém a ocorrência de mais um aborto e os resultados dos exames sorológicos para leptospirose levaram o proprietário a optar pela utilização da vacina contra leptospirose. Posteriormente, ainda no ano de 2015 não houve mais registro de abortos assim como durante todo o ano de 2016.

\section{DISCUSSÃO}

A obtenção do histórico do caso, os exames clínicos realizados, a visualização do agente no teste de Woo e identificação do Trypanosoma vivax por meio de teste molecular comprovaram

\begin{tabular}{|c|c|c|c|c|c|c|}
\hline \multirow{2}{*}{ Grupos } & \multicolumn{2}{|c|}{$\begin{array}{l}\text { Sorologia para } \\
\text { tripanossomose }\end{array}$} & \multicolumn{2}{|c|}{$\begin{array}{c}\text { Sorologia para } \\
\text { leptospirose }\end{array}$} & \multicolumn{2}{|c|}{$\begin{array}{c}\text { Sorologia para } \\
\text { neosporose }\end{array}$} \\
\hline & Positivo & Negativo & Reagente & $\begin{array}{c}\text { Não } \\
\text { reagente }\end{array}$ & Reagente & $\begin{array}{c}\text { Não } \\
\text { reagente }\end{array}$ \\
\hline \multirow{2}{*}{$\begin{array}{l}\text { Animais que } \\
\text { abortaram }\end{array}$} & (84\%) & $(16 \%)$ & $(92 \%)$ & $(8 \%)$ & $(36 \%)$ & $(64 \%)$ \\
\hline & $21 / 25$ & $4 / 25$ & $23 / 25$ & $2 / 25$ & $9 / 25$ & $16 / 25$ \\
\hline \multirow{2}{*}{$\begin{array}{l}\text { Animais } \\
\text { que pariram } \\
\text { normalmente }\end{array}$} & (84\%) & $(16 \%)$ & $(100 \%)$ & $(\%)$ & $(20 \%)$ & $(80 \%)$ \\
\hline & $21 / 25$ & $4 / 25$ & $20 / 20$ & $0 / 20$ & $4 / 20$ & $16 / 20$ \\
\hline \multirow{2}{*}{$\begin{array}{l}\text { Animais } \\
\text { prenhes }\end{array}$} & $(96 \%)$ & $(4 \%)$ & \multirow{2}{*}{ NR } & \multirow{2}{*}{ NR } & \multirow{2}{*}{ NR } & \multirow{2}{*}{ NR } \\
\hline & $24 / 25$ & $1 / 25$ & & & & \\
\hline \multirow{2}{*}{$\begin{array}{l}\text { Demais } \\
\text { animais do } \\
\text { rebanho }\end{array}$} & $(78,7 \%)$ & $(21,3 \%)$ & \multirow{2}{*}{ NR } & \multirow{2}{*}{ NR } & \multirow{2}{*}{ NR } & \multirow{2}{*}{ NR } \\
\hline & $85 / 108$ & $23 / 108$ & & & & \\
\hline \multirow{2}{*}{ TOTAL } & $(82,51 \%)$ & $(17,49 \%)$ & $(95,6 \%)$ & $(4,44 \%)$ & $(28,89 \%)$ & $(71,11)$ \\
\hline & $151 / 183$ & $32 / 183$ & $43 / 45$ & $2 / 45$ & $13 / 45$ & $32 / 45$ \\
\hline
\end{tabular}

NR = Não realizado. a ocorrência do surto de tripanossomose. Esse é o primeiro registro de surto no estado do Maranhão e comprova, conforme já informado com preocupação por outros autores, que a enfermidade encontra-se em ampla disseminação no Brasil. Guerra et al. (2008) haviam registrado a ocorrência do parasito em um bezerro no município de Itapecuru-Mirim, localizado na região centro-oeste do estado.

A semelhança dos sinais clínicos com outras enfermidades, a exemplo da anaplasmose e babesiose, que cursam com sintomatologia semelhante, sugere que a tripanossomose bovina possa estar sendo subdiagnosticada no estado e também no Brasil. Essa situação é agravada pelo fato de que os medicamentos utilizados no tratamento da anaplasmose e babesiose terem alguma eficácia sobre os tripanossomas, o que leva a parcial recuperação do animal e os equívocos associados ao diagnóstico.

As condições identificadas na propriedade, como ambiente propício aos vetores, a introdução de animais dos estados de Minas Gerais e Pernambuco, onde já haviam sido registrados importantes surtos da enfermidade, são aspectos importantes que provavelmente estiveram associados à introdução e disseminação do agente no rebanho. De Brito (2011) relata que a movimentação de animais infectados por T. vivax para áreas livres do agente é descrito como um fator responsável pela ampla distribuição geográfica e disseminação do parasita. A presença de um grande número de capivaras, já referenciada como um reservatório de tripanossoma (Silva et al. 2002), também deve ser considerada como uma possível forma de entrada do agente no rebanho, pois as capivaras e os bovinos coabitavam os pastos, na presença de grande quantidade de tabanídeos.

No Brasil, a ocorrência de tripanossomose em rebanhos leiteiros esteve muitas vezes associada ao uso indevido de agulhas na aplicação de medicamentos, a exemplo da ocitocina para facilitar a ejeção do leite de vacas mestiças (Graça 2014). Porém, essa prática em nenhum momento foi utilizada no rebanho em questão, o que sugere e reforça a possibilidade das moscas e mutucas terem tido uma participação importante na transmissão. Em bovinos, o T. vivax determina parasitemia mais alta do que em outras espécies e favorece a transmissão mecânica (Radostits et al. 2002). No entanto, não deve ser desconsiderada a possibilidade de contaminação dos animais na prática de utilização de uma agulha em diversos animais nas vacinações e vermifugações na propriedade.

Os sinais clínicos apresentados nos animais como salivação, secreção nasal mucosa, membros rígidos e perda de peso foram semelhantes aos já apresentados por outros autores durante relatos da enfermidade (Silva et al. 1997, Batista et al. 2008, Cadioli et al. 2012), inclusive a sintomatologia nervosa apresentada por um dos animais que está associada a presença do agente no tecido nervoso (Batista et al. 2007, 2008). A morte de animais com um curso clínico inferior a 48 horas e o relato de animais cronicamente doentes demonstra que a enfermidade se manifestou de forma aguda a crônica. Linhares et al. (2006) descreve que não há sintomas patognomônicos que possam auxiliar na realização de um diagnóstico preciso de T. vivax. Podem ocorrer casos agudos e levar o animal a morte ou progredir para uma fase subaguda e crônica. A doença pode ainda demonstrar caráter crônico desde o início da infecção.

A ocorrência de abortos sem a manifestação dos demais sinais clínicos da tripanossomose, situação referenciada 
pelo proprietário, sugere que esses poderiam também estar associados a outras doenças, como a leptospirose, pois altos títulos foram identificados nos animais testados. A positividade desses mesmos animais nos testes sorológicos para tripanossomose dificultou o diagnóstico dos casos de aborto. A presença do sorovar Hardjo na sorologia reforça a suspeita do envolvimento de leptospiras nos abortos e está de acordo com a queixa do proprietário referente ao aborto ser o único sinal clínico apresentado por alguns animais. De acordo com Miashiro (2013) no caso de infecção com esse sorovar a doença se manifesta de forma crônica, tendo como principal manifestação clínica o aborto e nascimento de bezerros fracos.

A presença da lagoa nas áreas de pastejo deve ser considerada também como um fator de risco para a leptospirose, pela presença das capivaras, pois a transmissão da leptospirose pode ocorrer a partir da ingestão de água ou alimentos contaminados com urina de animais infectados. De acordo com Albuquerque et al. (2017) as capivaras apresentam infecção crônica com baixos títulos e eliminação de bactérias por longo tempo e podem agir como reservatórios. Em trabalho recente Langoni et al. (2016) identificaram aglutininas anti-leptospiras em capivaras no Brasil e aponta para a necessidade de mais pesquisas para identificar a importância desses animais na transmissão da enfermidade para outros animais e o homem.

A identificação de animais positivos nos testes para o Neospora caninum e o histórico de cães terem acesso a fetos abortados e restos placentários, demonstra que esse agente também pode estar envolvido em alguns casos de aborto (Corbellini et al. 2000), porém a análise conjunta dos testes sorológicos realizados demonstrou que apenas um animal, entre os que abortaram, reagiu para neospora e foi sorologicamente negativo para leptospirose e tripanossomose, o que minimiza o risco dos abortos estarem associados a essa patologia.

O elevado número de animais sorologicamente positivos para tripanossomose $(82,51 \%)$ demonstra que praticamente todo o rebanho teve contato com o agente. No entanto, apesar do grande número de animais infectados, observou-se que poucos animais manifestaram os sinais clínicos mais frequentemente associados à enfermidade. 0 bom estado nutricional dos animais e a adoção no rebanho de boas práticas sanitárias provavelmente estiveram associados a uma resposta imunológica eficiente no momento do contato inicial dos animais com o agente, o que permitiu que estes conseguissem controlar a infecção, evitando a instalação de infecções secundárias e combatendo as formas clínicas mais graves da tripanossomose (Schenk et al. 2001). A alta infestação de carrapatos identificada no rebanho e o desconforto associado à presença de moscas e mutucas pode ter levado os animais a uma condição momentânea de estresse, capaz de reduzir as defesas do organismo e ocasionar o surgimento de sinais clínicos em alguns animais. Estudos demonstraram, mediante acompanhamento clínico, laboratorial e anatomopatológico de rebanhos bovinos infectados no estado de Mato Grosso, que diversos fatores influenciam para que a infecção cause danos aos animais, tais como, alimentação, formas de manejo, estresse e outras doenças que podem estar associadas à tripanossomíase, agravando o quadro clínico (Paiva et al. 2000). Schenk et al. (2001) não induziu sinais clínicos ou alterações bioquímicas em bovinos inoculados com T. vivax, indicando que os animais são capazes de estabelecer equilíbrio na relação parasita-hospedeiro quando em estado nutricional favorável.

A visualização do agente em apenas dois animais no teste de Woo, mesmo que a sorologia tenha sido alta no rebanho para T. vivax, está associada ao fato da baixa sensibilidade deste teste. De acordo com Radostits et al. (2002) a observação direta deve ser feita no estágio inicial da doença, quando o pico de parasitemia corresponde ao pico febril e é possível visualizar o agente. Dessa forma, esse teste deve ser associado ao teste molecular que apresenta elevada especificidade e consegue identificar a presença do parasita, mesmo que em pequena quantidade no organismo. Magona et al. (2002) destaca a importância da PCR como teste confirmatório, pois além de obter o diagnóstico definitivo, tem a função de caracterização morfológica e identificação da espécie envolvida na infecção.

A identificação de animais com baixos valores no hematócrito foi a principal alteração hematológica identificada no rebanho. Essa alteração também foi identificada por Linhares et al. (2006) em surto de tripanossomose por T. vivax no Tocantins. Baixos valores de hematócrito podem ser resultante da eritrofagocitose, hemólise intravascular imunomediada e em uma fase tardia, pela hematopoese inadequada (Salgado et al. 2011).

0 rápido estabelecimento das medidas de controle, entre elas a utilização das drogas tripanocidas, contribuiu para o controle do surto. Após o início da utilização das drogas não ocorreram mais óbitos e foi observada significativa melhora nos animais com sintomas da enfermidade. De acordo com Stephen (1986) em áreas onde a transmissão do T. vivax é realizada mecanicamente, o tratamento precoce nos períodos iniciais da doença, em que a parasitemia é sempre mais alta, provoca interrupção da transmissão mecânica por insetos, se este for o principal modo de transmissão. Deve-se ressaltar também como medida profilática importante na resolução dos problemas apresentados na propriedade a utilização das vacinas contra leptospirose, o que provavelmente foi determinante no controle dos abortos.

Apesar da dificuldade de contabilizar os prejuízos advindos das enfermidades diagnosticadas, pois esses envolvem mortes de animais, perda de material genético, redução da produção de leite e ganho de peso, infertilidade, ausência dos animais que abortaram nas linhas de ordenha e de suas crias para reposição ou comercialização, altos custos das drogas tripanocidas e despesas com assistência técnica e exames laboratoriais, ficou evidente que esses foram muito expressivos.

\section{CONCLUSÕES}

O estudo permitiu comprovar a ocorrência de mais um surto de tripanossomose bovina no Brasil.

A condição ambiental identificada numa propriedade, associada à intensificação da criação, favoreceu a ocorrência da tripanossomose e acarretou graves perdas produtivas.

O diagnóstico clínico da tripanossomose foi dificultado pela semelhança com outras enfermidades presentes na região e possível associação de dois ou mais agentes patológicos no mesmo paciente, o que ressaltou a importância do estabelecimento das medidas diagnósticas adequadas como forma de evitar a disseminação da enfermidade e reduzir maiores perdas econômicas. 


\section{REFERÊNCIAS}

Albuquerque N.F., Martins G., Medeiros L., Lilenbaum W. \& Ribeiro V.M.F. 2017. The role of capybaras as carriers of leptospires in periurban and rural areas in the western Amazon. Acta Tropica 169(1):57-61. http:// dx.doi.org/10.1016/j.actatropica.2017.01.018. PMid:28119048.

Batista J.S., Bezerra F.S.B., Lira R.A., Carvalho J.R.G., Rosado Neto A.M., Petri A.A. \& Teixeira M.M.G. 2008. Aspectos clínicos, epidemiológicos e patológicos da infecção natural em bovinos por Trypanosoma vivax na Paraíba. Pesq. Vet. Bras. 28(1):63-69. http://dx.doi.org/10.1590/S0100736X2008000100010.

Batista J.S., Riet-Correa F., Teixeira M.M.G., Madruga C.R., Simões S.D.V. \& Maia T.F. 2007. Trypanosomiasis by Trypanosoma vivax in cattle in the brazilian semiarid: description of an outbreak and lesions in the nervous system. Vet. Parasitol. 143(2):174-181. http://dx.doi.org/10.1016/j. vetpar.2006.08.017. PMid:16965857.

Cadioli F.A., Barnabé P.A., Machado R.Z., Teixeira M.C.A., André M.R., Sampaio P.H., Fidélis Junior O.L., Teixeira M.M. \& Marques L.C. 2012. First reporto of Trypanosoma vivax outbreak in dairy cattle in São Paulo state, Brasil. Revta Bras. Parasitol. Vet. 21(2):118-124. http://dx.doi.org/10.1590/ S1984-29612012000200009. PMid:22832751.

Carvalho A.U., Abrão D.C., Facury Filho E.J., Paes P.R.O. \& Ribeiro M.F.B. 2008. Ocorrência de Trypanosoma vivax no estado de Minas Gerais. Arq. Bras. Med. Vet. Zootec. 60(3):769-771. http://dx.doi.org/10.1590/S010209352008000300037.

Cole Junior J.R., Sulzer C.R. \& Pursell A.R. 1973. Improved microtechnique for the leptospiral microscopic agglutination test. Appl. Microbiol. 25(6):976980. PMid: 4736794.

Corbellini L.G., Driemeier D., Cruz C. \& Dias M.M. 2000. Aborto bovino por Neospora caninum no Rio Grande do Sul. Ciência Rural 30(5):863-868. http://dx.doi.org/10.1590/S0103-84782000000500021.

Cuglovici D.A., Bartholomeu D.C., Reis-Cunha J.L., Carvalho A.U. \& Ribeiro M.F. 2010. Epidemiologic aspects of an outbreak of Trypanosoma vivax in a dairy cattle herd in Minas Gerais state, Brazil. Vet. Parasitol. 169(3/4): 320-326. https://doi.org/10.1016/j.vetpar.2009.12.041. PMid: 20138431.

De Brito P.D. 2011. Efeito da infecção por Trypanosoma vivax sobre a ingestão de alimentos, conversão alimentar, ganho de peso e características de carcaça de ovinos infectados experimentalmente. Dissertação de Mestrado em Ciência Animal, Universidade Federal Rural do Semiárido, Mossoró, RN. 95p.

Galton M.M., Sulzer C.R., Santa Rosa C.A. \& Fields M.J. 1965. Application of a microtechnique to the agglutination test for leptospiral antibodies. Appl. Microbiol. 13(1):81-85. PMid: 14264852.

Graça D.S. 2014. Surto de Trypanossomose bovina em Minas Gerais. Escola de Veterinária, Universidade Federal de Minas Gerais, Belo Horizonte.

Guerra R.M.S.N.C., Feitosa Junior A.B., Santos H.P., Abreu-Silva A.L. \& Santos A.C.G. 2008. Biometry of Trypanosoma vivax found in a calf in the state of Maranhão, Brazil. Ciência Rural 38(3):833-835. http://dx.doi.org/10.1590/ S0103-84782008000300041.

Labruna M.B., Homem V.S.F., Heinemann M.B. \& Ferreira Neto J.S. 2000. Ticks (Acari: Ixodidae) associated with rural dogs in Urará eastern Amazon, Brazil. J. Med. Entomol. 37(5):774-776. http://dx.doi.org/10.1603/00222585-37.5.774. PMid:11004794.

Langoni H., Kuribara I.Y., Ferreira Lopes Correa A.P., Ullmann L.S., Sánchez G.P. \& Lucheis S.B. 2016. Anti-leptospirosis agglutinins in Brazilian capybaras (Hydrochoerus hydrochaeris). J. Venom. Anim. Toxins incl. Trop. Dis. 22(4):1-4. PMid:26819575.

Linhares G.F.C., Dias Filho F.C., Fernandes P.R. \& Duarte S.C. 2006. Tripanossomíase em bovinos no município de Formoso do Araguaia, Tocantins: relato de caso. Ciênc. Anim. Bras. 7(4):455-460.

Magona J.W., Mayende J.W. \& Walubengo J. 2002. Comparative evaluation of the antibody-detection ELISA technique using microplates precoated with denatured crude antigens from Trypanosoma congolense of Trypanosoma vivax. Trop. Anim. Health Prod. 34(4):295-308. http:// dx.doi.org/10.1023/A:1015630701923. PMid:12166331.

Miashiro A.F. 2013. Prevalência de leptospirose em rebanhos bovinos no Pantanal do Mato Grosso do Sul. Dissertação de Mestrado em Ciência Animal, Universidade Federal do Mato Grosso do Sul, Campo Grande, MS. 52p.

Paiva F., Lemos R.A., Oshiro A.E., Salvador S.C. \& Nakasato L. 1997. Ocorrência de Trypanosoma vivax em bovinos do estado de Mato Grosso do Sul. Revta Bras. Parasitol. Vet. 6(2):349-352.

Paiva F., Lemos R.A.A., Nakasato L., Brum K.B., Bernado K.C., Madruga C.R. \& Schenk M.A. 2000. Trypanosoma vivax em bovinos no Pantanal do estado de Mato Grosso do Sul. Revta Bras. Parasitol. Vet. 9:143-14.

Radostits O.M., Gay C.C., Blood D.C. \& Hinchcliff K.W. 2002. Clínica Veterinária. 9a ed. Guanabara Koogan, Rio de Janeiro, p.1194-1200.

Salgado B.S., Battaglia C.T., Stuchi R.S., Cadioli F.A., Rozza D.B. \& Machado G.F. 2011. What is your diagnosis? Lymphadenopathy in a cow with severe anemia. Vet. Clin. Pathol. 40(1):103-104. http://dx.doi.org/10.1111/j.1939165X.2011.00295.x. PMid:21291489.

Schenk M.A.M., Mendonça C.L., Madruga C.R., Kohayagawa A. \& Araújo F.R. 2001. Avaliação clínico-laboratorial de bovinos nelore infectados experimentalmente com Trypanosoma vivax. Pesq. Vet. Bras. 21(4):157161. http://dx.doi.org/10.1590/S0100-736X2001000400006.

Serra-Freire N.M. 1981. Oiapoque, outro foco de Trypanosoma vivax no Brasil. Revta Bras. Med. Vet. 4(4):30-31.

Silva R.A.M.S., Sanchez V. \& Dávila A.M.R. 2003. Métodos de diagnósticos parasitológicos das tripanossomoses bovinas e equinas. Circ. Téc. 41, Embrapa Pantanal, Corumbá, MS. 3p.

Silva R.A.M.S., Seidl A., Ramirez L. \& Davila A.M.R. 2002. Trypanosoma evansi e Trypanosoma vivax: biologia, diagnóstico e controle. Embrapa Pantanal, Corumbá, MS. 137p.

Silva R.A.M.S., Silva J.A., Freitas J., Morales G., Eulert E., Ybanes R., Montenegro A., Dávila A.M.R. \& Amirez L. 1997. Tripanossomose bovina por Trypanosoma vivax no Brasil e Bolívia: sintomas clínicos, diagnósticos e dados epizootiológicos. Ministério da Agricultura, Brasília. 17p.

Stephen L.E. 1986. Trypanosomiasis: a veterinary perspective. Pergamon Press, New York. 533p.

Ventura R.M., Paiva F., Silva R.A.M.S., Takeda G.F., Buck G.A. \& Teixeira M.M.G. 2001. Trypanosoma vivax: characterization of the spliced-leader gene of a Brazilian stock and species-specific detection by PCR amplification of an intergenic spacer sequence. Exp. Parasitol. 99(1):37-48. https://doi. org/10.1006/expr.2001.4641. PMid: 11708832.

Woo P.T.K. 1970. The haematocrit centrifugue technique for the diagnosis of African trypanosomosis. Acta Tropica 27(4):384-386. PMid:4396363. 